\title{
Cortical Thickness in Pre Central and Post Central Human Brain Cortex of Patient with Headache: MRI finding
}

\author{
Mohammed Ubaid Hamza ${ }^{1}$, Fadhil Husam Ahmed ${ }^{2}$ \\ ${ }^{1}$ Assistance Prof. Dr. MBChB, M.Sc., F.I.B.M.S, Al-Farahidi University, College of Medical Techniques, \\ Department of Technical Medical Lab, ${ }^{2}$ Assistance Lecturer; M.Sc. Anatomy \& Histology, Al-Farahidi University, \\ College of Medical Techniques, Department of Technical Medical Lab
}

\begin{abstract}
It is new clear that the brain of the headache sufferers are different from those of people without headache, the imaging study showed thickening in specific area of brain related to communication of sensory processing called somatosensory cortex (post central region) in this study we examine 36 patient, 28 of them have headache of variable duration, 8 healthy patient used as control (i.e. has no headache). The result has found that the cortex area of brain is thicker in pre central and post central cortex, especially predominant in post central cortex and this thickening isincreasing with duration of headache and not related to the age of patient, the explanation of these structural changes will be discussed in this study.
\end{abstract}

Keywords: Headache, Migraine, Cerebral Cortex, Sensory Neurons, Motor Neurons, MRI.

\section{Introduction}

From anatomical point of view the pre central gyrus lies immediately anterior to the central sulcus and is known as the motor area .large motor nerve cells in this area control voluntary movement on the opposite side of the body. In motor area the body represented in an invested position that the feet located in the upper part and those controlling the movement of face and hand in the lower part. The post central gyrus lies immediately posterior to the central sulcus, and is known as sensory area. The small nerve cell in this area receive the interpret sensation, temperature, touch and pressure from opposite side of body ${ }^{(1)}$. The motor area is region from which most of cortico spinal and cortico nuclear nerve fiber arise, and the region where low intensity stimulation most readily elicits movements of contra lateral side of the body. Sensory area is the region to which the impulse ascending in the medial lemniscus and spino thalamic tracts are transmitted ${ }^{(2)}$.

\footnotetext{
Corresponding Author:

Fadhil Husam Ahmed,

Al-Farahidi University, College of Medical Techniques, Iraq/Baghdad

e-mail: fadhilhussam@gmail.com
}

Headache is very widespread disease, and according to the WHO, we have 243 types of headache, one of the most common this disorder of the nervous system. Migraine effects $15-45$ of women and 6-8 man ${ }^{(3-6)}$. The path physiology of migraine is not yet fully understood, and the available treatment and cure attach are not optimal. Migraine patient have visual symptom in $94 \%$ of cases ${ }^{(7)}$, but symptom may involve sensory and speech deficits ${ }^{(8)}$.

Recently two published article reporting cortical thickness differences in migraine sufferers ${ }^{(9}$ and 10$)$. In the first paper ${ }^{(9)}$ we examined the visual areas involved in motion processing were thickened migraineurs. the second article ${ }^{(10)}$ reported increase thickness in somatosensory cortex of migraineurs, especially in the area the head and face representation. What do these cortical thickness increase mean and what are the potential implication, indeed be explain in several ways which are discussed later.

In 2007 researcher have identified specific differences in brain of migraine sufferers linked to the processing of sensory information including pain. in earlier research Harvard medical school investigator used MRI to show structural differences between brain of people with and without migraine, specially the imaging showed thickening in a specific area of the brain 
related to communication of sensory processing called somatosensory cortex. It is not clear if migraine cause the brain changes or if the brain differences causes migraine. Researcher Nouchin Hadjikhani that is the big question she says "A person could be born with these cortical differences making them susceptible to migraines, later in life, but we just don't know".

In newly reported imaging study researcher compared the brain of 24 people with migraine and 12 people withoutmigraine. they found that somatosensory was an average of $21 \%$ thicker in migraine sufferer. The thickness changes were especially pronounced in the part related to sensation of head and face ${ }^{(11)}$.
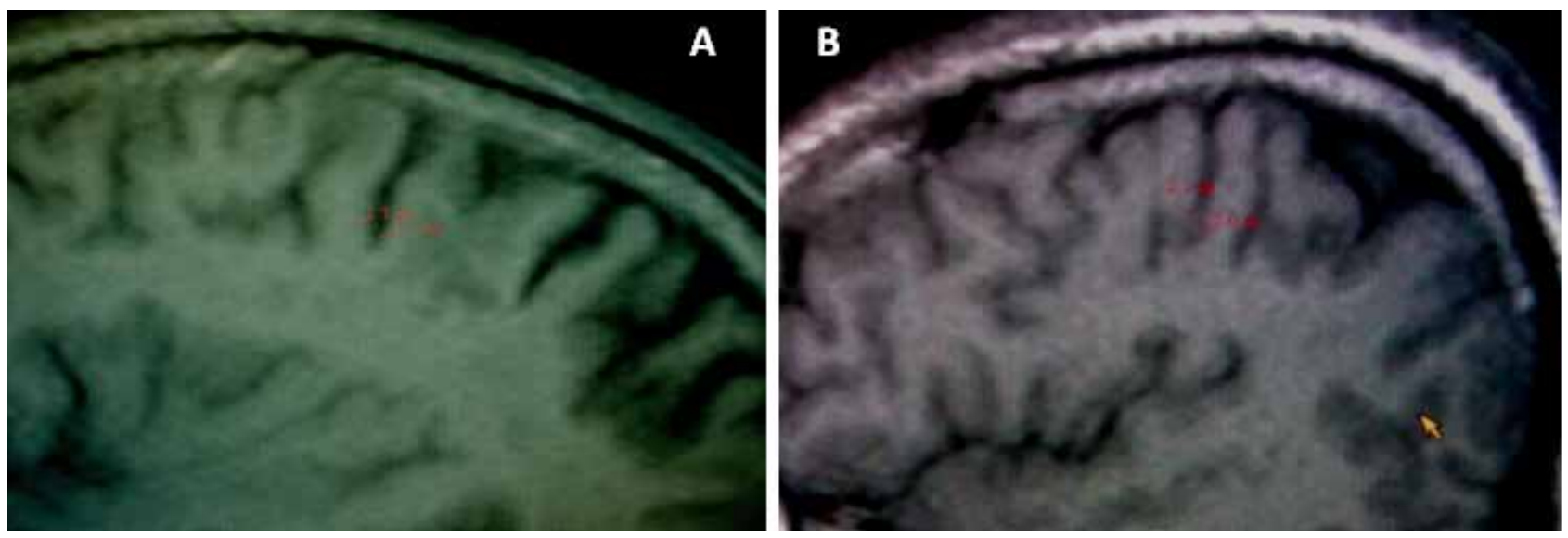

Fig. 1: MRI of normal person, age 40-44years, has no headache showing normal pre central and post central cortical thickness.

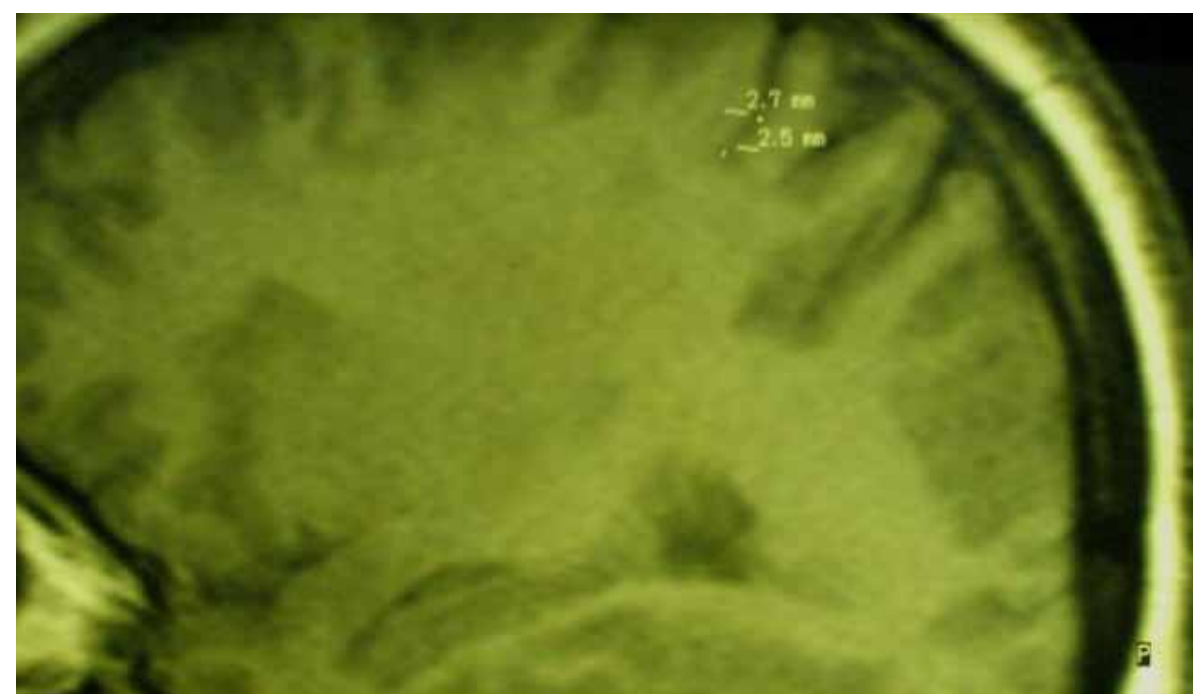

Fig. 2: MRI of patient age 46 year has headache of one-year duration showing slight increasing cortical thickness of pre central and post central cortical area. 

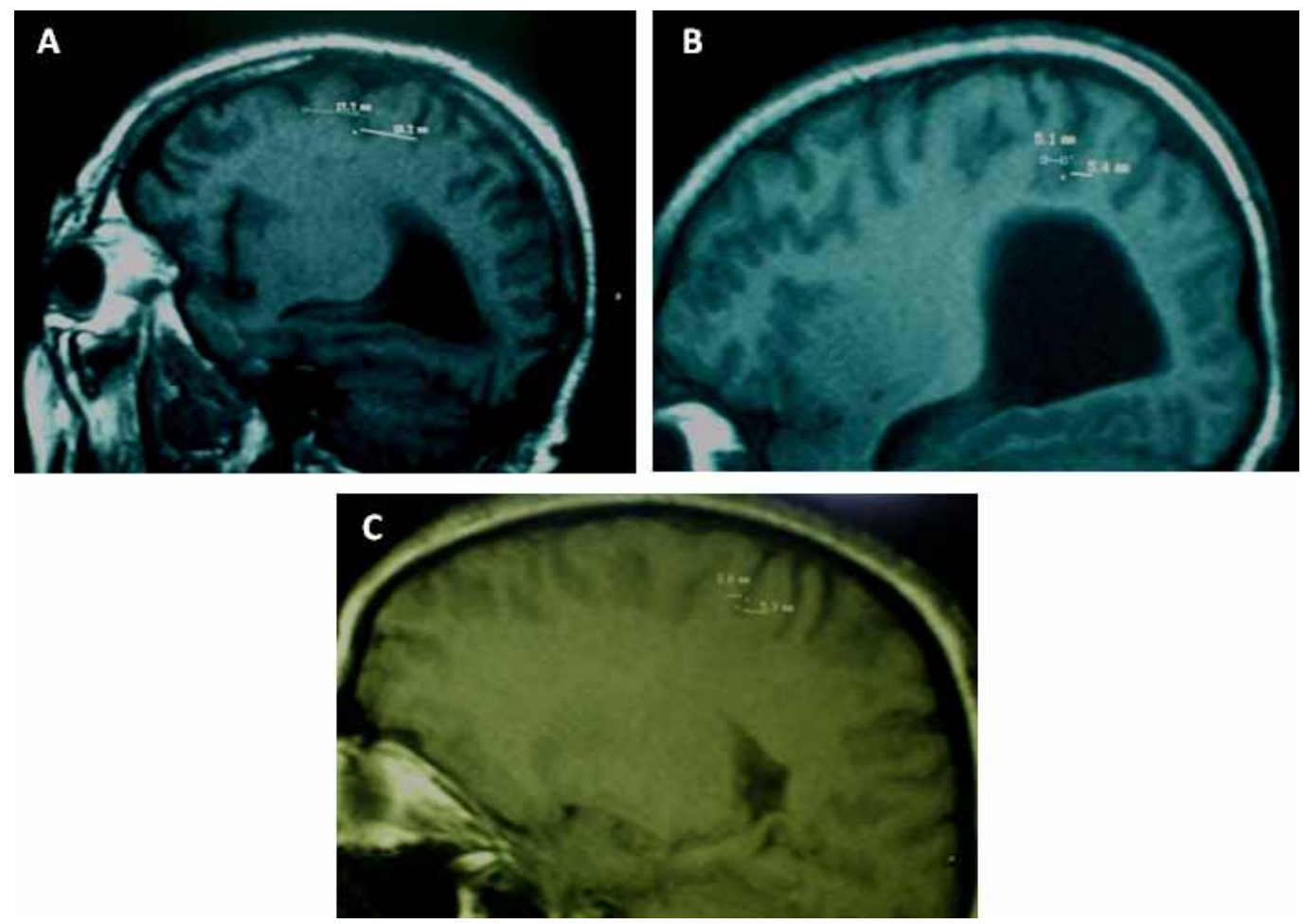

Fig. 3: MRI of patient, (A); Age 64 years has headache of 4-year duration showing increasing thickness of pre central and post central gyrus). (B); Age 17 years has headche of 5 years duration showing increasing

thickness pf pre central and post central cortical region). (C); Age 26 years has headache of 10 years duration showing increasing thickness in pre central and post central cortical regions).

Table [1]: Patients with headache.

\begin{tabular}{|c|c|c|c|c|c|c|}
\hline $\begin{array}{l}\text { Thickness of } \\
\text { post-central } \\
\text { gyrus (mm) }\end{array}$ & $\begin{array}{l}\text { Thickness of } \\
\text { pre-central } \\
\text { gyrus }(\mathrm{mm})\end{array}$ & $\begin{array}{c}\text { Thickness of } \\
\text { post-central } \\
\text { GM (mm) }\end{array}$ & $\begin{array}{c}\text { Thickness of } \\
\text { pre-central GM } \\
(\mathbf{m m})\end{array}$ & $\begin{array}{c}\text { Duration of } \\
\text { headache } \\
\text { (years) }\end{array}$ & $\begin{array}{l}\text { Age of patient } \\
\text { (years) }\end{array}$ & No. of patient \\
\hline 15 & 12 & 3.6 & 3.2 & 3 & 47 & 1 \\
\hline 21 & 16 & 2.8 & 2.5 & 1 & 46 & 2 \\
\hline 15 & 17 & 3 & 2 & 2 & 20 & 3 \\
\hline 24 & 19 & 2.4 & 2.8 & 2 & 40 & 4 \\
\hline 19 & 16 & 3 & 3.4 & 4 & 22 & 5 \\
\hline 16 & 20 & 2.9 & 2.6 & 3 & 37 & 6 \\
\hline 19 & 13 & 5.4 & 5.1 & 5 & 17 & 7 \\
\hline 15 & 11 & 2.6 & 2.4 & 1 & 28 & 8 \\
\hline 22 & 13.6 & 4.2 & 3 & 6 & 62 & 9 \\
\hline 19 & 16 & 5.3 & 3.6 & 10 & 26 & 10 \\
\hline 19.2 & 17.7 & 2.9 & 2.6 & 4 & 64 & 11 \\
\hline 19 & 17 & 2.5 & 2.4 & 2 & 66 & 12 \\
\hline 18 & 13 & 4.2 & 3.6 & 4 & 49 & 13 \\
\hline 13 & 10 & 2.8 & 2.5 & 1 & 14 & 14 \\
\hline 20 & 17.1 & 3.3 & 2.8 & 3 & 53 & 15 \\
\hline 17.3 & 14 & 3.5 & 3 & 3 & 20 & 16 \\
\hline 17 & 12 & 4.2 & 3.7 & 4 & 20 & 17 \\
\hline
\end{tabular}




\begin{tabular}{|c|c|c|c|c|c|c|}
\hline $\begin{array}{l}\text { Thickness of } \\
\text { post-central } \\
\text { gyrus (mm) }\end{array}$ & $\begin{array}{l}\text { Thickness of } \\
\text { pre-central } \\
\text { gyrus }(\mathrm{mm})\end{array}$ & $\begin{array}{c}\text { Thickness of } \\
\text { post-central } \\
\text { GM }(\mathbf{m m})\end{array}$ & $\begin{array}{c}\text { Thickness of } \\
\text { pre-central GM } \\
(\mathrm{mm})\end{array}$ & $\begin{array}{c}\text { Duration of } \\
\text { headache } \\
\text { (years) }\end{array}$ & $\begin{array}{l}\text { Age of patient } \\
\text { (years) }\end{array}$ & No. of patient \\
\hline 16 & 14 & 3.5 & 3.2 & 2 & 17 & 18 \\
\hline 13 & 16 & 3.6 & 2.5 & 1 & 54 & 19 \\
\hline 17 & 13 & 3.3 & 3.1 & 2 & 22 & 20 \\
\hline 13 & 14 & 2.8 & 2.4 & 1 & 53 & 21 \\
\hline 17 & 18 & 3.5 & 3.4 & 2 & 33 & 22 \\
\hline 16.3 & 13 & 3.2 & 3.7 & 3 & 25 & 23 \\
\hline 16 & 11.5 & 2.3 & 3.2 & 2 & 61 & 24 \\
\hline 19 & 14.1 & 4.4 & 4.2 & 5 & 43 & 25 \\
\hline 15 & 12.1 & 3.7 & 3.3 & 3 & 45 & 26 \\
\hline 14 & 12 & 2.6 & 2.5 & 2 & 32 & 27 \\
\hline 17.3 & 15 & 3.6 & 3.5 & 4 & 43 & 28 \\
\hline
\end{tabular}

Table [2]: Normal person (without headache).

\begin{tabular}{|c|c|c|c|c|c|}
\hline $\begin{array}{c}\text { post-central gyrus } \\
(\mathbf{m m})\end{array}$ & $\begin{array}{c}\text { pre-central gyrus } \\
(\mathbf{m m})\end{array}$ & $\begin{array}{c}\text { post-central GM } \\
(\mathbf{m m})\end{array}$ & $\begin{array}{c}\text { pre-central GM } \\
(\mathbf{m m})\end{array}$ & Age (years) & No. of patient \\
\hline 13 & 12 & 1.8 & 2.2 & 54 & 1 \\
\hline 12.7 & 13.2 & 2.3 & 2.6 & 32 & 2 \\
\hline 13.2 & 11.1 & 2.5 & 2.6 & 43 & 4 \\
\hline 11.6 & 13 & 2.4 & 2.7 & 40 & 5 \\
\hline 11.3 & 12.4 & 2.2 & 2.5 & 46 & 6 \\
\hline 12.2 & 10.9 & 2.6 & 2.2 & 44 & 7 \\
\hline 10.1 & 11.5 & 2.3 & 2.4 & 51 & 8 \\
\hline 13.2 & 12.8 & 2.2 & & & 5 \\
\hline
\end{tabular}

Table [3]: Patient with headache and normal patient.

\begin{tabular}{|l|c|c|c|c|}
\hline & $\begin{array}{c}\text { Pre central cortical } \\
\text { thickness mm. }\end{array}$ & $\begin{array}{c}\text { Pre central gyrus } \\
\text { mm. }\end{array}$ & $\begin{array}{c}\text { Post central cortical } \\
\text { thickness mm. }\end{array}$ & $\begin{array}{c}\text { Post central gyrus } \\
\text { mm. }\end{array}$ \\
\hline Normal (without headache) & $2.2-3.0$ & $10.9-13.2$ & $1.8-2.6$ & $10.1-13.2$ \\
\hline With headache & $2.0-5.1$ & $11.0-20.0$ & $2.4-5.4$ & $13.0-24.0$ \\
\hline
\end{tabular}

Table [4]: Duration of headache.

\begin{tabular}{|c|c|c|c|c|}
\hline $\begin{array}{c}\text { Duration of } \\
\text { headache(year) }\end{array}$ & $\begin{array}{c}\text { Pre central cortical } \\
\text { thickness mm. }\end{array}$ & Pre central gyrus mm. & $\begin{array}{c}\text { Post central cortical } \\
\text { thickness mm. }\end{array}$ & Post central gyrus mm. \\
\hline One year & $2.4-2.5$ & $10.0-16.0$ & $2.6-3.6$ & $13.0-21.0$ \\
\hline $6-10$ year & $3.0-3.6$ & $13.6-17.7$ & $4.2-5.3$ & $17.0-24.0$ \\
\hline
\end{tabular}

\section{Conclusion}

Patients with headache have pre central, post central cortical thickness, and pre central and post central gyrus more than normal patients. Fig. [1,2, and 3].
More specific post central cortical thickness and post central gyrus is more than pre central cortical thickness and gyrus, Fig. [3]. 
The pre central, postcentral, cortical thickness and gyrus is increased with duration of headache and not related to the age of patients. Table [1 and 4].

\section{Discussion}

Structural changes in migraineurs is unknown. diagnosis of migraine relies on patient history and finding different in brain of migraineurs might help to contribute the basic research aimed at better understanding the patho-physiology of migraine.

Headache is one of the man's most common affection the frequency of disabling headache is explain in part by rich nerve supply to head (including efferent nerve fibers from trigeminal,glossopharyngeal, vagus and upper three cervical nerve). And in part psychological implication of head pain, causing anxiety about even modest headache, head pain can be result of either intra or extra cranial disease in the distribution of any of above nerves ${ }^{(12)}$.

The first possible explanation is that migraineurs have brain structural differences compared with healthy people due to their genetic background ${ }^{(12-14)}$.

Anatomical changes underlying increases in cortical thickness may include an increasenumber and/or density of neuronal and/or glial cells in certain part of the cortex [fig. 1,3].this focal dysplasia may render the cortex more excitable, one of the leading hypo theses in migraine patho physiology is indeed that the brain of migraineurs are hyper excitability ${ }^{(15-17)}$.

The hypo thesis of hyper excitable brain in migraine is supported by fact that preventing treatment using drugs likely to reduce the cortical excitability are beneficial in migrainewith or without aura. independent from etiological nature of the cortical thickness increase in migraineurs, it is worth noting that the anatomical modification that we described were present both in migraine, substrate for these clinical entities ${ }^{(18)}$.

So, understanding the patho physiology of migraine is an essential step in design of drugs at preventing and treating migraineaffectively ${ }^{(19)}$.

The result indicates that there is thickening of pre and post central cortex in patient with headache [fig. 1]. And from review of literature, at seem that the article concentrates on post central cortex and specifically on somatosensoryarea ${ }^{(12)}$,[table1, fig.2 and 3].

Dr. Hidijikani and Collages ${ }^{(12)}$ said that there was no difference in cortical thickness in pre central cortex in patient with headache. but in my research, there is changes in pre central cortex. And these changes can be explained according to the hypo thesis of rich nerve supply to head ${ }^{(11)}$. And increase number and/or density of neuronal cells ${ }^{(16)}$ in addition to hyper excitable ofbrain in migraineurs patients.

US study have found the cortex are brain is thickening in people who have migraine compared to those who do not the research don't know whether the difference causes the migraine or having migraine over the years has led to the difference in brain structure.

Reported headache attach may lead to or to be the result of these structural changes in the brain said Hadjikhani in a prepared treatment, she said that most of those people had been suffering from headache since childhood .so long term overstimulation ofthe sensory field in the cortex could explain these changes.

Using MRI, researchers had already discovered therewere structural differences between brain of people with headache and people without headache or the other hand, it could also be that their brain structure changed progressively for some other reason and this led to the headache.

However, regardless of the cause the result show that the sensory areas of the brain are important components in headache. this explain why patient with headache often also have other pain disorder such as back pain, jaw pain, and other sensory ${ }^{(3)}$. Problems, where the skin becomes so sensitive that even a gentle breeze can be painful [Hadjikhani] ${ }^{(12)}$.

Other studies have also revealed the cortex of people who have certain condition is different, for instance people with multiple sclerosis and Alzheimer disease have thinner cortex. The area become thicker with extensive learning and motor training ${ }^{(11)}$.

\section{Recommendation:}

1. Early diagnosis and treating causes of headache in order to preventing a complication and side effect like weakness of memory.

2. Using complimentary medication which content drug and certain behavior training exercises which related to relaxation and preventing tension,stress, anxiety with continues using physical exercises to increase the ability of person in order avoiding the 
result of damage or injury to cortical area of brain.

\section{Conflict of Interest: Nil}

Source of Funding: Self

Ethical Clearance: Taken from Al-Farahidi University Ethical committee

\section{Reference}

1. Richard S. Snell.clinical anatomy, $7^{\text {th }}$ ed. Lippin. cott. William and Wilkins. (2004). Pp:810-815.

2. Romanes G.J. Cunningham's manual of practical anatomy $15^{\text {th }}$ ed. Oxford New York Tokyo oxford university press.(1986). Pp: 252-256.

3. Warshow W, Button WN. Cutting the costs of migraine role of the employee health unit J. Ocup. Enrron. Med. 40(11). (1998). Pp: 943-953

4. Stewart Wf, Lipton R.B. prevalence of migraine headache in the united states relation to age, income, race and other sociodemographic factors Jama 267 (1), (1992). pp: 64-69.

5. Michel p, Dartigues Jf. international absenteeism due to headache in migraine: results from the mig-access French national cohort cephalalgia 19(5),(1999). pp:503-510

6. HuxH Markson LE, Lipton RB. Burdon of migraine in the united states disability and economic costs. Arch. Intern. Med (1999). pp: 159(8),813-818.

7. Jensen $\mathrm{K}$, Tfelt- Hansent $\mathrm{p}$, olesenj.classic migraine, A prospective recording of sympotoms. Acta Neurol. Scans.(1986). 73(4), 359-362.

8. Vincent. MB, Hadjikhani $\mathrm{N}$, migraine, aura and related phenomena. beyond scotomata and scintillations, cephalalgia (2007). 27 (12), 13681377
9. Granziera C, Dasilva AF, Synder J, Tuch DS, Hadjikhani N. Anatomical alterations of the visual motion processing network in migrain with and without auraplos med. (2006). 3(10), E 402.

10. Dasilva AF, GranzieraC, Snyder J, Hadjikhan N. thickening in the somtosensory cortex of patient with migrain. Neurology (2007). 69 (21),19901995

11. Hadijikhani N, Sanchez Del Rio M.: Mechanism of Migraineaura revealed byfunction MRI in human visual cortexproe. Natl Acad. Sci. USA (2001). 98 (8),4687-4692

12. Kors EE., Melberg A, Vanmolkot KR: childhood epilepsy, familial hemiplegia migrain, cerebellar ataxia, and a new CACNAIA mutation.Neurology (2004). 63(6), 1136-1137

13. Wessman M, Kaunisto MA, Kollela M, palotie A,the molecular genetics of migraine.Ann. Med. (2004). 36(6), 462-473

14. Goadsby $\mathrm{Pj}$. The migrainous brain: what you see is not au get? Plos Med. (2006). 3(10), E404.

15. Welch K.M. contemporary concepts \& migraine pathogenesis.Neurology(2003), $16 \quad(8$ supp104),S2-S8.

16. Aurora Sk. Welch K.M. Al-Saved F. The Threshold for phosphenes in lower in migraine.Cephalagia (2003). 23(4), 258-263

17. Battell: I., Black KR,Wray Sh. Trauscranial magnetic stimulation of visual area V5 in migraine . Neurology (2002). 58(7), 1066-1069

18. Sanchez - Del: Rio M, Moskowitz MA New insights into migraine pathophysiology.(2006). Curr. opvn. Neurol. 19(3),294-298.

19. Moskowits MA.:The 2006 Thomas Willis lecture: the adventures of a translational researcher in stroke and migraine. stroke (2007) 38(5), 1645-1651. 